\title{
Literature as a Pedagogical Tool in Medical Education: The Silent Patient Case
}

\author{
Suhad Daher-Nashif (D)
}

check for

updates

Citation: Daher-Nashif, Suhad. 2021 Literature as a Pedagogical Tool in Medical Education: The Silent Patient Case. Humanities 10: 95. https:// doi.org/10.3390/h10030095

Academic Editor: Albrecht Classen

Received: 2 April 2021

Accepted: 4 August 2021

Published: 8 August 2021

Publisher's Note: MDPI stays neutral with regard to jurisdictional claims in published maps and institutional affiliations.

Copyright: (C) 2021 by the author. Licensee MDPI, Basel, Switzerland. This article is an open access article distributed under the terms and conditions of the Creative Commons Attribution (CC BY) license (https:/ / creativecommons.org/licenses/by/ $4.0 /)$.
Population Medicine Department, College of Medicine, QU Health, Qatar University, Doha 2713, Qatar; snashif@qu.edu.qa

\begin{abstract}
The arts have seen increasing use in medical education over the last 4 decades. Literature in particular is now frequently used as an educational tool in different medical humanities programmes. This paper analyses Alex Michaelides' novel The Silent Patient with the goal of examining the professional issues presented in this psychological thriller and how the novel's themes can be used to prompt discussion among medical students about professionalism and ethics in psychiatric settings. Following Strauss and Corbin's qualitative procedure for conventional content analysis, this study employs content analysis of the literary text. The process of analysis began with open coding in which codes were assigned to all relevant sentences and paragraphs addressing professionalism in working with silent patients in psychiatry. These codes were then analysed to identify five major themes: multidisciplinary teamwork; therapy for the therapist; patient-centred care for silent patients; communication with silent patients; professional challenges in working with silent patients. The paper concludes that The Silent Patient novel represents important issues related to ethics and professionalism in working with silent patients in psychiatric settings. The novel can be used as a creative tool to guide discussion surrounding these issues. The paper argues that although the impact of its use is short-term, literature can make a significant contribution by provoking thought and discussion about professional and ethical aspects of practising medicine and caring for patients.
\end{abstract}

Keywords: The Silent Patient; professionalism; ethics; literature; medical education

\section{Introduction}

Unexpressed emotions will never die.

They are buried alive, and will come forth later,

In uglier ways

Sigmund Freud, Beyond the Pleasure Principle (1920)

Alex Michaelides opens part two of his debut novel The Silent Patient (2019, p. 53) with this quote, reminding the reader that in psychiatry, a patient's silence does not indicate emptiness nor an absence of emotion, but may itself be a way to communicate, a way to express, and, many times, a way to scream. In other words, patients' screams are not always heard.

In The Silent Patient, two narrators, an artist named Alicia and a psychotherapist named Theo, tell two merging stories. One night, after Alicia's husband, Gabriel, comes home from work, Alicia shoots him five times in the face and then stops speaking. She becomes a silent patient, hospitalised at the Grove psychiatric hospital in North London. Theo, a forensic psychotherapist, follows Alicia's story and is intent on reaching her. He joins her multidisciplinary care team at the Grove as a psychotherapist. The reader eventually learns that Theo entered Alicia and Gabriel's home the night of the murder to confront Gabriel, who had had an affair with his wife, Katheryn. He tied Gabriel up, forcing him to choose whether he or Alicia would die; Gabriel answered, 'I don't want to die' (Michaelides 2019), condemning Alicia. This metaphorical death was what silenced Alicia, who would later 
say, 'I remained silent. How could I talk? Gabriel had sentenced me to death. The dead don't talk' (Michaelides 2019). Rather than carry out his threat, Theo untied Alicia's hands and left the house; she picked up the gun and shot Gabriel.

This paper asks how The Silent Patient represents professionalism and the ethics of working with silent patients, and how these representations can be used to promote discussions amongst medical students. A conventional content analysis of the novel was used to answer this question. (For more information about the methods, see Section 4).

In general, medical students can learn a great deal about professional practices and ethics of working with patients by reading, reflecting on, and discussing literature. Although there is a lack of evidence-based studies on the long-term impact of using art works in general (Daher-Nashif 2020) and literature in particular in medical education (Ousager and Johannessen 2010), a wide range of studies encourage it and cite its valuable influence on the development of medical students' professional, ethical, and personal skills (Skelton et al. 2000a, 2000b; Evans 2003; Shapiro et al. 2015). For example, Shapiro et al. (2015) claim that 'within a medical education framework, literature is highly suited to assist learners in questioning conventional thinking and assumptions about various dimensions of professionalism' (p. 2). This claim is based on the authors' study of the role and contribution of literature in teaching professionalism in medicine. The authors argue that the use of literature in medical education can bring into question the meaning of 'professionalism' itself, as well as its virtues. Hunter et al. (1995) note that faculty in one-third of all US medical schools teach literature, and that while its use is concentrated in the preclinical years, literature can be used in teaching from the first day of medical school through residency. Literature provides 'access to the values and experiences of physicians, patients, and families; it calls for the exercise of skill in observation and interpretation, develops clinical imagination, and, especially through writing, preserves fluency in ordinary language and promotes clarity of observation, expression, and self-knowledge' (Hunter et al. 1995, p. 1061).

Despite generally positive attitudes, more evidence-based studies should be conducted on the value of using literature in medical education. In a literature review on the topic of 'humanities in undergraduate medical education,' Ousager and Johannessen (2010) reviewed 245 studies and concluded that 'evidence on the positive long-term impacts of integrating humanities into undergraduate medical education is sparse' (p. 988). They also warned that this lack of evidence might pose a threat to the continued development of the use of humanities-related activities in undergraduate medical education. Even if the impact of its use is short-term, literature can make a significant contribution by provoking thought and discussion about professional and ethical aspects of practising medicine and caring for patients.

Academic work in psychiatry and psychotherapy is rich with analytical writings on the condition of 'the silent patient' and on professionalism in working with this condition. The first of these writings date to the late 1950s and early 1960s (Waldhorn 1959; Loewenstein 1961). Despite that, and the fact that several scholars have noted the value of using literature in teaching in the field of psychiatry more generally (Tucker 1994; Podrug 2005; Douglas 2008), evidence-based studies on using literature to teach about the specific condition of silent patients is very scarce. The present study aims to examine how professionalism and ethics are represented in the novel The Silent Patient, and inform about how it can be used as a pedagogical tool to promote discussions on related issues among medical students.

One of the first studies on using literature with psychiatric students as a complementary resource was completed by Rodenhauser and Leetz (1987), who used Walker Percy's novel, The Moviegoer (1961), as a tool to stimulate discussions in a reading group of new residents in psychiatry. After 2 years of running the group, they recommended 'regular inclusion of literature study groups in Psychiatry Residency Training Programs' (p. 243). Douglas' (2008) study examines Charles Dickens' presentation of psychiatry and outlines the mental disorders possibly suffered by the characters under ICD 10 diagnostic headings. Another example comes from Podrug (2003), who uses Shakespeare's Hamlet to highlight 
the importance of the teaching process rather than only the content to medical students in psychiatry. In this article, I aim to examine how The Silent Patient can be used in medical education, identify the topics related to professionalism and ethics that are raised by the author, and explore how the novel can be used to stimulate discussions on these topics amongst medical students. This paper is a response to the call by scholars such as Ousager and Johannessen (2010) for more evidence-based discussions on the contribution of novels to teaching medical students professionalism and ethics. This is the first study that uses qualitative research methods and analyses the content of The Silent Patient to examine its potential addition to medical humanities resources.

\section{Results}

The conventional content analysis of the novel identified five main themes of professionalism and ethics related to working in psychiatric settings. In this section, I will present these themes and suggest ways of using them in promoting and stimulating discussion and reflection among medical students.

\subsection{Multidisciplinary Teamwork}

Developing and maintaining professionalism in a multidisciplinary team requires a strong professional identity and clarity of each team member's role. Studies on professional identity confirm a correlation between professional identity and commitment to work (Caza and Creary 2016). The Silent Patient presents the role of each member of a multidisciplinary psychiatric team. For example, Theo Faber, the protagonist of The Silent Patient's second half, is a psychotherapist. Through his perspective, the text presents the different goals of psychotherapy in a psychiatric institution. His initial approach is concerned with 'fixing' (p. 12) and 'finding' (p. 27) the patient, and subsequently with 'making her [Alicia] think and feel' (p. 65). Theo uses these words each time he describes his therapy goals and objectives for Alicia to the senior psychiatrist at the Grove, Diomedes. His words reflect the common approach of attempting to 'normalise' the patient, to bring her behaviour back into line with the expectations of society. A different perspective on the role of therapy is offered by Indira, a consultant psychotherapist at the Grove, who says, 'Therapy isn't just about talking [ ... ] it's about providing a safe space-a containing environment. Most communication is nonverbal' (p. 73). These different perspectives and further therapeutic approaches can be discussed with medical students, with a discussion of the history and philosophy behind each and their pros and cons. In addition, the novel presents the role of nurse, senior psychiatrist, and art therapist. For example, Diomedes' role as a senior psychiatrist is presented as the case manager and the supervisor who is responsible for resolving conflicts and disagreements among the different team players. Another example is the role of the art therapist, who enables patients' expression through art in order to understand their feelings, thoughts, and experiences.

Furthermore, the analysis found that the novel describes approaches to orchestrating the team's work, and differentiates between the various professional roles by presenting the responsibilities of each member both through the narrator's voice and through dialogue between characters. The novel also presents disagreements and conflicts between different visions and approaches to patients, which will be presented later. Teamwork and conflicts can be discussed with medical students by linking what the novel suggests with what they have learned in theoretical readings and what they have witnessed in the medical field.

It is important to mention here that The Silent Patient's description of the roles of the various professionals involved in Alicia's care highlights what is not part of their responsibilities as well as what is. In particular, the novel defines what a psychotherapist should avoid by addressing Theo's confusion of the role of the therapist with that of detective. The novel clarifies that along the journey to uncover the causes and triggers for the patient's silence and mental condition, the therapist should remember Diomedes' advice to Theo: '[ ... ] you're going about this the wrong way. You're asking questions, 
searching for clues, like it's a detective story [ ... ] As therapist, your only goal is to be present and receptive to your feelings as you sit with her.' (p. 129).

\subsection{Therapy for the Therapist}

The Silent Patient presents a case of how therapists should also care for themselves and take part in their own therapeutic process. Caring for one's own mental health is presented as part of a professional journey that may also be influenced by the psychological processes a therapist experiences with their patients. Theo begins his therapeutic journey before he decides to become a psychotherapist, as he deals with the physical and mental violence he experienced as a child and adolescent at the hands of his abusive father. Reflecting on why he chose psychotherapy as a profession, he says, 'The real motivation was purely selfish. I was on a quest to help myself. I believe the same is true for most people who go into mental health. We are drawn to this profession because we are damaged-we study psychology to heal ourselves. Whether we are prepared to admit this or not is another question' (p. 14). Theo's confession can be a good entry point for a classroom discussion about why students have chosen to study medicine, or why they chose psychiatry as their residency. Honest reflection about career choices contributes to students' development of their professional philosophies and poses important questions about self-fulfilment, self-esteem, and satisfaction.

The novel's exploration of therapy for the therapist reflects the writer's goal of normalising mental illness. Ruth, Theo's psychotherapist, highlights this normalisation by saying, 'We are made up of different parts, some good, some bad [ ... ] a healthy mind can tolerate this ambivalence and juggle both good and bad at the same time. Mental illness is precisely about a lack of this kind of integration-we end up losing contact with the unacceptable parts of ourselves' (p. 35). The use of the first person and of the word 'losing' defines mental illness as a condition that every one of us may be exposed to or experience and over which we have little control. This collective vulnerability is reflected in Theo's statement: 'I felt desperately sorry for her, and those like her-for all of us, all the wounded and the lost' (p. 36). Such an approach to mental illness can be presented to trigger medical students to discuss their own attitudes towards mental illness and mental health. Several studies document the prevalence of mental health stigma among medical students (Hankir et al. 2014; Kopera et al. 2015), which positive group discussions can contribute to breaking down (Harrison et al. 2017)

The novel also provides examples of the related process of professional supervision, especially at the beginning of the therapist's career. Diomedes serves as Theo's primary supervisor throughout the novel, offering help and support, reflection and critique, and collaboration to resolve complicated situations with patients. He describes this process by saying, "That is the purpose of supervision [ . . ] to help you unpick the strands of wool-to see what is yours and what is hers' (p. 384). This description can help students to reflect on their own supervision processes. Residents in psychiatry, for example, can easily link and compare their experiences with the presented experience in the novel.

\subsection{Patient-Centred Care}

\subsubsection{Meeting the Patient's Needs and Values}

The Silent Patient showcases some components of patient-centred care, which is defined by the Institute of Medicine as 'Providing care that is respectful of, and responsive to, individual patient preferences, needs and values, and ensuring that patient values guide all clinical decisions' (Baker 2001). In the course of Alicia's treatment, before she speaks, Theo is respectful and responsive to Alicia's needs and preferences. The novel suggests alternative ways to identify a silent patient's needs, preferences, pains, and comforts, by being attentive to the patient's bodily clues, facial expressions, and other types of nonverbal communication. A defining feature of the patient-centred approach is working to meet the needs of the patient using appropriate tools. Theo hears about Alicia's desire to paint from her friend Jean-Felix, the manager of the gallery where she displays her art, who suggests 
to Theo, 'If you really want to get Alicia to talk ... give her some paint and brushes. Let her paint. That is the only way she'll talk to you. Through her art' (p. 152). Theo suggests and eventually succeeds in providing Alicia with a 'room of her own' where she can paint and express herself. He also enquires about the effectiveness and appropriateness of using art therapy sessions with her. As an artist, she requires a specific approach to art therapy appropriate to her artistic and cognitive skills. When Theo tells Alicia that she is to be given her own art room, she smiles for the first time. By referring to these representations, students can discuss how these themes are witnessed in the medical field, what they think about the way they are represented in the novel, and how they can be improved in the field. Patient-centred care can also be a topic to promote discussion on what medical settings offer psychiatric patients for self-fulfilment, the opportunity to have a 'room of their own', and how patients' self-fulfilment can be implemented even when the resources are limited.

\subsubsection{The Patient's Context and History}

Part of patient-centred care is taking into consideration the patient's family and cultural context as a way to tailor the intervention to the needs and values of the patient. Understanding the patient's status and needs in psychiatry requires continuous communication with the family in order to build an understanding of the patient's developmental history and needs, especially in cases where the patient lacks the ability to express themselves and make decisions. At one point, Theo visits Alicia's house and meets her cousin Paul and her aunt Lydia, who raised her after her mother died in a car accident. This meeting prompts Theo to continue to reflect on the importance of understanding Alicia's past. He says: 'Within these walls her personality had been formed' (p. 131), and explains that this visit to her childhood home was a key for him to reveal what happened to shape her, make her into the person she became-a person capable of murder.

The Silent Patient shows how context and childhood experiences can cause long-term impacts and highlights the importance of looking at the patient's history. The text reveals how a psychotherapist may be able to understand what led a patient to develop mental illness. An example is when Theo says:

I wrote down another word: CHILDHOOD. [ . . . ] The seeds of what happened [ ... ] Murderous rage, homicidal rage, is not born in the present. It originates in the land of memory, in the world of early childhood, with abuse and mistreatment, which builds up a charge over the years, until it explodes-often at the wrong target. (p. 39)

Theo learns that Alicia's father committed suicide after his wife's death, and that prior to his suicide, in a drunken state, he once said: 'My girl [ . . ] my poor girl, my Eva ... why did she have to die? Why did it have to be her? Why didn't Alicia die instead?' (p. 255). Hearing her father say this 'killed' Alicia. When she begins speaking, she says to Theo: 'He killed me [ ... ] Dad just killed me' (p. 256). This interaction illustrates the power of words and how painful and harmful they can be, particularly the words of a parent to a child. Theo reflects on this when he says:

I imagine it-hearing your father, the very person you depend upon for your survival, wishing you dead. How terrifying that must be for a child, how traumatising-how your sense of self-worth would implode, and pain would be too great, too huge to feel, so you'd plod, and repress it, bury it [ ... ] but one day, all the hurt and anger would burst forth, like fire from dragon's belly-and you'd pick up a gun. (p. 256)

Alicia picks up a gun and shoots her husband after he metaphorically kills her, just as her father had.

Looking into patients' personal life, considering their sociocultural background, and understanding their childhood experiences are among the components of a holistic and culturally competent health care system. Using the way family was approached and 'investigated' by the psychotherapist in the novel can be an entry point to a discussion 
of these professional and ethical topics with students. Theo's childhood traumas and his personal life shaped his behaviour with his patient, Alicia. Such a scenario can be used to stimulate students to discuss how to separate personal life from professional life: who is a competent therapist, is a traumatised therapist competent to treat patients or should he/she first treat him/her self, and more.

\subsection{Communication with Silent Patients}

\subsubsection{Non-Verbal Communication}

Alicia's first smile in response to the news of her art room is a form of nonverbal communication that gives Theo clues about her preferences and needs. The Silent Patient provides examples of the different types of communication that exist beyond the verbal with patients in general and with silent patients in particular. The silent patient is a familiar condition in psychiatry, and there are several reasons patients may present with this condition, including fear, emotional overload, lack of verbal skills, and personality type. Sometimes, persistent silence is a symptom of an illness such as major depression or post-traumatic stress disorder (PTSD). In The Silent Patient, this condition is brought on by the trauma that Alicia experiences of being metaphorically killed by the people closest to her, her father and her husband. In general, a patient's silence is challenging for psychotherapists and psychiatrists, especially in cases where they consistently fail to help the patient to speak again. Diomedes illustrates this when he reacts to Theo's first expression of interest in helping Alicia by saying, 'You are not the first. I believed I would succeed. Alicia is a silent siren, my boy, luring us to the rocks, where we dash our therapeutic ambition to pieces [ ... ] she taught me a valuable lesson in failure' (p. 32). Through this statement, students can reflect on the power and agency of patients in general and patients' silence in particular. Furthermore, they can discuss limits and potential weaknesses of psychotherapists and psychiatrists in front of a patient's silence and failure in treating patients.

The novel provides examples of silence as a way to express attitudes, feelings, and needs. For example, in his first meeting with Alicia, Theo describes how just being present, and being silent like her, is a way to win her trust. He resists the 'urge to fill the void by talking. Instead, by remaining silent and just sitting there, I hoped to communicate something else, something nonverbal' (p. 75). Despite her silence, Alicia is shown to be quite capable of expressing her feelings and needs. Before she begins to speak, among other nonverbal expressions of thought and emotion, she smiles when she loves an idea; she responds aggressively and physically to enforce boundaries, to defend herself, and to express anger; and she moves physically closer or farther from others according to her comfort.

As her therapist, Theo uses several tools to understand what Alicia has gone through and interpret her thoughts and intentions: he reads her diaries, he tries to interpret and understand her paintings and link them to her condition and to the murder she committed, and he reads every possible nonverbal bodily expression. For example, he says, 'and I wondered about Alicia's purpose in giving me the journal to read. She was communicating something' (p. 227). Another example of the use of silence as a means of expression is when Theo returns Alicia's diary after he reads it and says, 'I'm on your side, Alicia [ ... ] you know that, don't you?' Afterwards, he reflects on this, saying, 'She didn't say anything. I took that as a yes' (p. 239). Behavioural medicine is rich with writings about challenging patients and approaches to communicate with them respectfully and effectively. Reading this novel can provide medical students with an opportunity to discuss this issue. The silent patient is one type of such challenging patient, which can be used as a case study to learn about alternative communication strategies and tools, and about understanding and using body language with patients in medical settings in general and psychiatric settings in particular. 


\subsubsection{Boundaries with Patients}

It is important to set and maintain awareness of boundaries in working with patients, especially in psychiatry, where transgression and countertransference by therapists are possible. Transgression and countertransference are psychological processes that take place between psychotherapists and patients. Theo describes one instance of transgression by remarking, 'to stand here in the courtyard and smoke with her did feel like a transgression. I was probably imagining it, but I felt we were being watched' (p. 271).

Countertransference is the redirection of a psychotherapist's feelings toward a patient or a therapist's emotional entanglement with the patient. For example, Theo asks Indira, 'And how do you feel about Alicia?' She answers, 'I find myself feeling very maternal towards her. That's my countertransference, that's what she brings in me' (pp. 72-73). Therapists have to be aware of these processes, lest the professional boundaries between therapist and patient become blurred. As Theo reflects, 'We were crashing through every last boundary between therapist and patient. Soon it would be impossible to tell who was who' (p. 265). At one point in the story, Diomedes shows disbelief in a story that Alicia tells, and Theo is shocked by Diomedes' disbelief. Diomedes recognises the countertransference happening and says to Theo, 'You're in deep with Alicia, and your feelings are bound up with hers like a tangled ball of wool' (p. 384).

Mirroring is another process that may take place between therapist and patient. Theo describes an experience of mirroring, saying that 'Her silence was like a mirror-reflecting yourself back to you. And it was often an ugly sight' (p. 94). In addition to the need to maintain professional behaviour and boundaries between therapists and patients, the novel raises the additional ethical issue of non-reported knowledge of the patient prior to the commencement of the therapeutic relationship. This topic is of high importance, especially in small or tightly knit communities, where patients and health care providers have high probabilities of personal relationships prior to the treatment process. In the novel, this is seen in the actions of Christian, Alicia's psychiatrist. Prior to the murder event and Alicia's hospitalisation, Christian was a friend of Gabriel, who approached him for help when Alicia repeatedly reported seeing a stranger watching her from the park near their home. Because Gabriel never saw the stranger himself, he suspected that Alicia had mental health issues. Christian treated her and was paid by Gabriel without reporting his payment. Theo then reads about this situation in Alicia's diary, but he also shows unethical behaviour by not reporting it. Instead, he uses this information to threaten Christian and extract benefits from this privileged knowledge throughout the rest of the novel. Ethics of friendship, kinship, and reporting are very important issues to discuss with medical students. Using the novel to trigger this discussion is a creative and enjoyable tool to use.

\subsection{Professional Challenges in Working with Silent Patients}

The conflict between Theo and Christian is one of several challenges presented in the novel. The main point of conflict is the contradiction between Theo's declared goal of helping Alicia to speak again and Christian's goal of keeping her safe from suicide and preventing her from causing physical harm to other patients. A conflict arises between Christian's desire to increase Alicia's medications to prevent risk and Theo's desire to reduce the use of medications (and thus their side effects) in the hope that this would enable her to 'feel', 'think', and speak. This dispute is resolved through tense discussion between the characters and through the careful, behind-the-scenes intervention of the senior psychiatrist, Diomedes. Diomedes describes his view of this conflict by telling Theo, 'We'll see how he [Christian] reacts. Psychiatrists don't often respond well to being told how to medicate their patients. Of course, I can overrule him, but I don't tend to do that-let me broach the subject with him subtly' (p. 66).

Another challenge that psychiatrists may experience, which is presented clearly in the novel, is violence. Violence in the psychiatric context may present itself in three ways: patient to patient, worker to patient, patient to worker, and worker to worker. An example of patient to patient violence is when Alicia attacks Elif, another patient, and causes severe 
damage to her eye. This occurs in reaction to Elif sabotaging the first painting that Alicia creates in her new art room. Elif is also known for her verbal violence toward Alicia and others in the Grove. Christian, the psychiatrist, uses Alicia's display of violence as an opportunity to discredit Theo's skills and put Alicia back on her medications, ignoring the actions that provoked the situation. He also proposes putting Alicia in seclusion. Theo rejects Christian's decisions and defines the suggestion that she should be isolated as an example of worker to patient violence, saying, 'She was provoked [ ... ] It was an isolated incident [ . . ] Putting Alicia in seclusion isn't just cruel-it's barbaric' (pp. 199-200). Through this condemnation of cruelty, the author highlights the violence that exists in the ability of professionals to use power against patients. It is, in fact, this kind of power that leads to silencing the patient again after she has begun to speak. The thriller ends with Theo engaging in the most unethical and unprofessional behaviour a therapist could possibly engage in: when he realises that Alicia has identified him as the intruder who led her to kill Gabriel, he murders her with an overdose of morphine, silencing her again.

The third type of violence raised by the author is the violence displayed by patients against health care workers. Violent acts by patients can have many causes, the most common being alcohol or drug abuse, hostility, paranoid thoughts, and acute psychosis (Cornaggia et al. 2011). In his first meeting with Alicia, Theo insists that the head psychiatric nurse, Yuri, not remain in the room in order to protect him from Alicia. After he has spoken to her briefly, she attacks him: 'Before I could finish the thought, Alicia leaped from the chair. She threw herself toward me, hands outstretched like claws. I had no time to move or get out the way [ ... ] Her fingers were tight around my neck, gripping-I groped for the alarm but couldn't reach it' (p. 77). Theo interprets this attack as an attempt to say something, to communicate. He asserts to the team, 'Well, obviously Alicia was reacting to me on some level. I believe it shows us how much she wants to communicate' (p. 81). Taking risks, making individual decisions, and interpreting patient violence are all important topics to reflect upon and discuss with medical students.

\section{Discussion}

Through this qualitative conventional content analysis of the psychological thriller The Silent Patient, I have identified how professionalism and ethics of working with silent patients are represented in the novel and offered ways of using these themes to trigger and enrich discussions among medical students and residents in psychiatry. As a behavioural scientist and instructor of a course on medicine and the arts in a college of medicine, I find this thriller to be a potential text to use with medical students in medical humanities courses and communication skills courses.

The issues raised in The Silent Patient relate to the professional and ethical concerns of both healthcare workers and patients. One of the most challenging conditions for health workers in psychiatry is the condition of the silent patient. Recent writings on 'silent patients' address the importance of implementing Gadow's concept of existential advocacy (Gadow 1989), which respects individual patient concerns and identities. Through this approach, access to the patient's voice is possible only when the therapist's voice, like the patient's, arises from the experience of embodiment. In Gadow's words, 'Silent patients cannot be represented by the words of bodiless advocates' (Gadow 1989). Michaelides' work represents Gadow's (1989) existential advocacy approach, implementing its essential principle of knowing as much as possible about the patient by looking into their past through research and personal inquiries to the family. Through this approach, the silent patient is recognised as a person rather than just as an objectified body with psychosis that precludes agency and personhood (Benner 2002). The responsibility to approach patients as empowered subjects rather than simply objects of the medical system is an important topic of discussion for students in psychiatry, especially where it concerns patients who have no capacity to speak. The various ways of knowing a silent patient are important topics for discussion with medical students, as are the questions of who might help professionals 
learn more about the person behind the silence and where, when, and how to approach them.

Among the realistic professional issues raised in this thriller is the common conflict between using medications to ensure patients' safety and reducing medication to reduce side effects and allow them to think and express themselves clearly. While discussing this and other ethical issues, it is always important to consider the socio-demographic factors and circumstances influencing the mental health of each patient. In their content analysis of 223 comments on antipsychotic drugs, Moncrieff et al. (2009) reported that 'adverse subjective effects play a central role in the experience of taking antipsychotic drugs and may be related to the drugs' desired benefits' (p. 102).

Aside from the use of medication as part of treatment, the topic of punishing patients for their violent acts is another issue to raise with medical students. Michaelides presents the conflict between the psychiatrists, who favour punishing Alicia by putting her in seclusion, and the psychotherapist, who sees this act as barbaric and cruel. Fletcher et al. (2017) argue that seclusion is among the most restrictive practices used in response to aggression in psychiatric inpatient settings. They describe the international work being completed on changing policies and reducing the use of such practices, and suggest an alternative model called Safewards, which includes a set of 10 interventions designed to deal with inpatient aggression. Seclusion is a topic of significant disagreement amongst healthcare workers. For example, Happell and Koehn (2011) claim that the negative impact of seclusion on patients is increasingly being acknowledged, but it also receives wide support from nurses as a necessary behaviour management strategy - even though their study also found that nurses acknowledge the negative impact of seclusion on patients. Nurses agreed that patients would feel 'scared, angry, confused, helpless, punished, disempowered, out of control, controlled by others, and frightened by the seclusion process' (p. 116).

The disagreement recounted in the novel regarding the use of the seclusion room is an example of the many disagreements amongst multidisciplinary teams in psychiatry that occur in reality. Past studies report that conflicts between multidisciplinary professionals' goals and intervention pathways are commonplace in psychiatric settings (Jones 2006). Disagreements and ways to manage them are other topics to be discussed with students, and Michaelides provides several examples of ways to avoid crises amongst team members by highlighting supervision and wise management on the part of the senior psychiatrist. An additional challenge faced by staff in psychiatric settings is violence committed by patients toward other patients or staff members. There are various aspects of this issue that can be discussed with students, including the reasons and triggers for the violence, appropriate reactions by the staff being attacked, immediate and long-term response plans, the education of patients in how to react appropriately to violence from another patient, and ways to protect staff and patients from physical harm. Lastly, one of the issues that is presented and can play a potential topic for discussion with students is the ability and willingness to find alternative channels of communication and alternative strategies to reach patients aside from verbal comunication. The Silent Patient suggests a wide range of possibilities, with the most important being learning how to listen to a patient's silence.

\section{Materials and Methods}

This study used qualitative content analysis of literary text, following Strauss and Corbin's (1998) procedure for conventional content analysis. In conventional content analysis, coding categories are derived directly from the text data (Hsieh and Shannon 2005). With a directed approach, the analysis is inductive and starts with relevant research findings and existing categories as guidance for initial codes (Hsieh and Shannon 2005). The author of this study is a behavioural scientist teaching ethics and professionalism in a college of medicine in the Middle East. The professional background, as well as the long and rich experience in qualitative methods and content analysis, qualifies the author to reliably identify ethical and professional issues in the novel. The process of conventional content analysis began with open coding through which codes were assigned to all relevant 
sentences and paragraphs addressing professionalism and ethics in psychiatry. This stage was followed by axial coding, which gathered all of the related codes together. Lastly, in the third stage, themes of analysis were created. These themes contained subcategories that emerged from the axial coding stage. As a tool to validate qualitative findings, the author debriefed her results with a psychiatrist who had read the thriller prior to the discussion.

Funding: This research received no funding.

Conflicts of Interest: The author declares no conflict of interest.

\section{References}

Baker, Alastair. 2001. Crossing the Quality Chasm: A New Health System for the 21st Century. British Medical Journal 323: 1192-92. [CrossRef]

Benner, Patricia. 2002. Caring for the silent patient. American Journal of Critical Care 11: 480-81. [CrossRef] [PubMed]

Caza, Barker Brianna, and Stphanie Creary. 2016. The Construction of Professional Identity. Electronic Version. Cornell University, SHA School, pp. 259-85. Available online: https:/ / ecommons.cornell.edu/handle/1813/71987 (accessed on 10 March 2021).

Cornaggia, Cesare Maria, Massimiliano Beghi, Fabrizio Pavone, and Francesco Barale. 2011. Aggression in psychiatry wards: A systematic review. Psychiatry Resarch 189: 10-20. [CrossRef]

Daher-Nashif, Suhad. 2020. Doctors' challenges during infectious disease outbreaks: Medical education insights from realistic fiction movies. Advances in Medical Education and Practice 12: 265. [CrossRef] [PubMed]

Douglas, Brian. 2008. Dickens' characters on the couch: An example of teaching psychiatry using literature. Medical Humanities 34: 64-9. [CrossRef]

Evans, Martyn. 2003. Roles for literature in medical education. Advances in Psychiatric Treatment 9: 380-85. [CrossRef]

Fletcher, Justine, Mathew Spittal, Lisa Brophy, Holly Tibble, Stuart Kinner, Steve Elsom, and Bridget Hamilton. 2017. Outcomes of the Victorian Safewards trial in 13 wards: Impact on seclusion rates and fidelity measurement. International Journal of Mental Health Nursing 26: 461-71. [CrossRef]

Gadow, Sally. 1989. Clinical Subjectivity: Advocacy with Silent Patients. Nursing Clinics of North America 24: 535-41.

Hankir, Ahmed Khaldoon, Amy Northall, and Rashid Zaman. 2014. Stigma and mental health challenges in medical students. Case Reports. [CrossRef]

Happell, Brenda, and Stefan Koehn. 2011. Impacts of Seclusion and the Seclusion Room: Exploring the Perceptions of Mental Health Nurses in Australia. Archives of Psychiatric Nursing 25: 109-19. [CrossRef]

Harrison, Carole A., Yvonne Hauck, and Rebekah Ashby. 2017. Breaking down the stigma of mental health nursing: A qualitative study reflecting opinions from western Australian nurses. Journal of Psychiatric and Mental Health Nursing 24: 513-22. [CrossRef]

Hsieh, Hsiu-Fang, and Sarah E. Shannon. 2005. Three approaches to qualitative content analysis. Qualitative Health Resources 15: 1277-88. [CrossRef]

Hunter, Kathryn, Rita Charon, and John Coulehan. 1995. The study of literature in medical education. Journal of the Association of American Medical Colleges 70: 787-94. [CrossRef]

Jones, Adrian. 2006. Multidisciplinary team working: Collaboration and conflict. International Journal of Mental Health Nursing 15: 19-28. [CrossRef]

Kopera, Maciej, Hubert Suszek, Erin Bonar, Maciej Myszka, Bartłomiej Gmaj, Mark Ilgen, and Marcin Wojnar. 2015. Evaluating explicit and implicit stigma of mental illness in mental health professionals and medical students. Community Mental Health Journal 51: 628-34. [CrossRef]

Loewenstein, Rudolph M. 1961. The Silent Patient: Introduction. Journal of American Psychoanal Association 9: 2-6. [CrossRef]

Michaelides, Alex. 2019. The Silent Patient. New York: Macmillan Publishers.

Moncrieff, Joanna, David Cohen, and John Mason. 2009. The subjective experience of taking antipsychotic medication: A content analysis of Internet data. Acta Psychiatrica Scandinavica 120: 102-11. [CrossRef] [PubMed]

Ousager, Jakob, and Helle Johannessen. 2010. Humanities in Undergraduate Medical Education: A Literature Review. Academic Medicine 85: 988-98. [CrossRef]

Podrug, Dinko. 2003. Hamlet as process: A novel approach to using literature in teaching psychiatry. Psychiatry: Interpersonal and Biological Processes 66: 202-13. [CrossRef] [PubMed]

Podrug, Dinko. 2005. Through Hamlet to Narrative Medicine and Neuroscience: Literature as a Basic Science of Psychiatry. Psychiatric Times 22: 23-23.

Rodenhauser, Paul, and Kenneth L. Leetz. 1987. Complementing the education of psychiatry residents: A study of novels, plays and films. Journal of Psychiatric Education 11: 243-48. [CrossRef]

Shapiro, Johanna, Lois Nixon, Stephan Wear, and David Doukas. 2015. Medical professionalism: What the study of literature can contribute to the conversation. Philosophy, Ethics, and Humanities in Medicine 10: 1-8. [CrossRef] [PubMed]

Skelton, John, Macleod John, and Cathryn Thomas. 2000a. Teaching literature and medicine to medical students, part II: Why literature and medicine? The Lancet 356: 2001-3. [CrossRef] 
Skelton, John, Macleod John, and Cathryn Thomas. 2000b. Teaching literature and medicine to medical students, part I: The beginning. The Lancet 356: 1920-22. [CrossRef]

Strauss, Anselm, and Juliet Corbin. 1998. Basics of Qualitative Research: Techniques and Grounded Theory Procedures for Developing Grounded Theory, 2nd ed. Thousand Oaks: Sage Publications.

Tucker, William. 1994. Teaching Psychiatry Through Literature. Academic Psychiatry 18: 211-19. [CrossRef]

Waldhorn, Herbert F. 1959. The Silent Patient. Journal of American Psychoanal Association 7: 548-60. [CrossRef] 